\title{
The Annual Temperature Regime of Natural Physical Cavity and New Possibilities of its Energy Utilization
}

\author{
Milan Bielek, Boris Bielek, Juraj Híreš, Ján Szabó \\ Slovak University of Technology in Bratislava \\ Faculty of Civil Engineering \\ e-mail: milan.bielek@stuba.sk, boris.bielek@stuba.sk,juraj.hires@stuba.sk,jan.szabo@stuba.sk
}

\begin{abstract}
Natural physical cavity. Quantification of annual temperature regime of natural physical cavity by in-situ experiment. Annual course of temperature of outdoor climate. Annual course of maximum temperature of natural physical cavity of optimal south-west orientation. Concept of new possibilities for energy utilization of air from natural physical cavities. Two-stage system for utilization of renewable energy sources.
\end{abstract}

Key words: natural physical cavity, double-skin transparent faced, experiment in-situ, renewable energy sources

\section{Introduction to the problem of the paper, its subjects and goals}

Development of a new facade technology of double-skin facades based on the application of natural physical cavities leads us to a deeper understanding of their theory. This deeper understanding of the theory of natural physical cavities leads only through new knowledge acquired by long-term in-situ experiment in the field of their annual energy regime and that under the conditions of convective flow and also under the conditions of co-effect of wind. This in-situ experiment was realized on the building of the headquarters of National Bank of Slovakia in Bratislava - fig. 1.

SUBJECT of the paper is therefore a natural physical cavity and that at least of a corridor type (width $0.6<\mathrm{w}(\mathrm{m})<1.5)$ - fig. 1 .

GOAL of the broadly conceived problem, part of which is this paper, is :

1. Quantification of its annual temperature regime in four distinctive seasons on the basis of in-situ experiment and that also in the relation to the model of outdoor climate in the form of test reference year for the locality of Bratislava, 
2. Confronting the possibility of utilizing the energy regime of natural physical cavity for the function of heat pump with primary energy of thermally conditioned AIR from the physical cavity - fig. 2 .

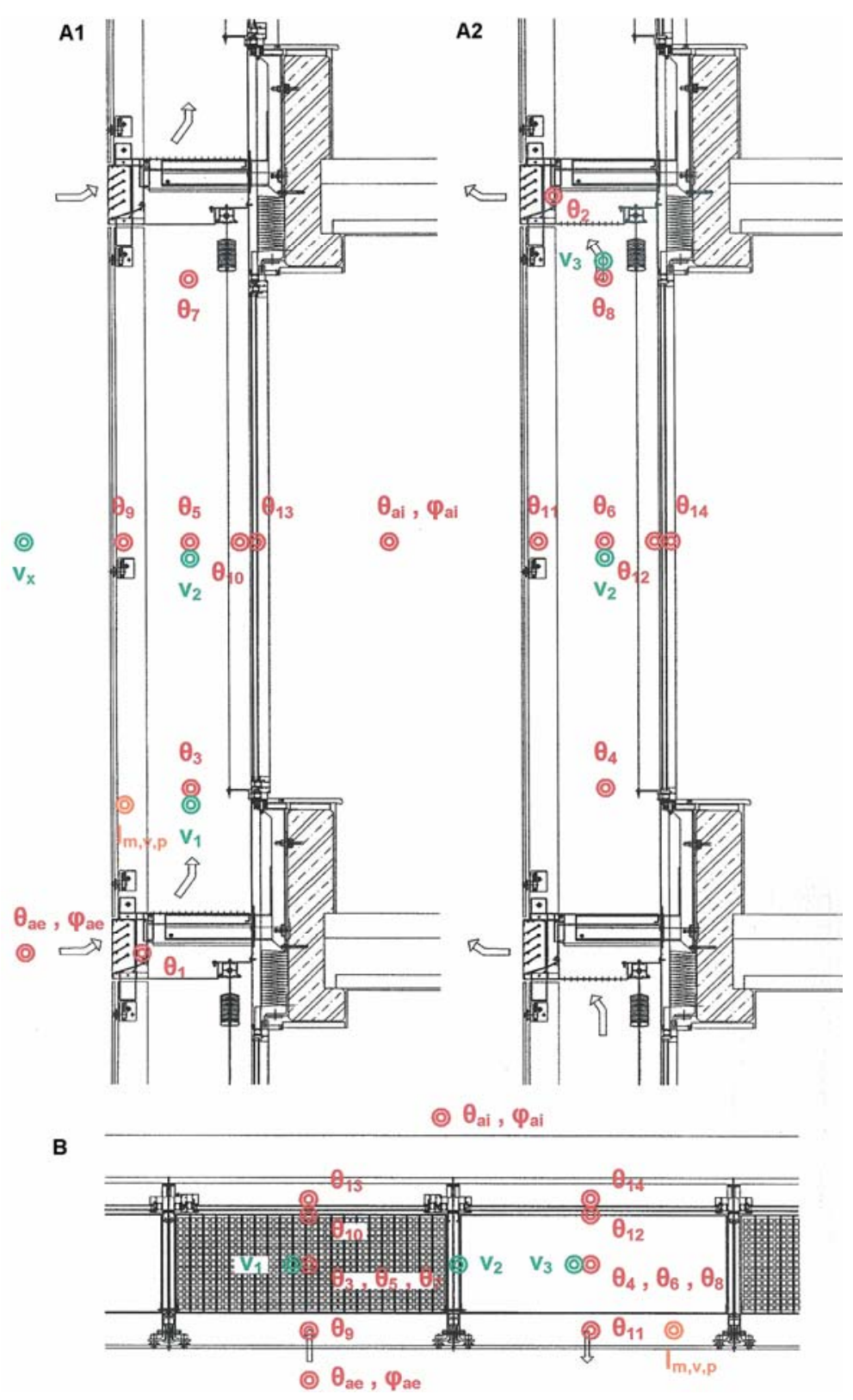

Figure 1: Experimentally monitored physical parameters of the cavity of double-skin transparent façade of corridor type (SWW orientation).

A1 - vertical section - inlet module, A2 - vertical section - outlet module, B - horizontal section of inlet and outlet module.

$\theta_{\mathrm{ae}} \approx \theta_{1}$ - temperature of air entering into the cavity (inlet module) $\left({ }^{\circ} \mathrm{C}\right)$

$\theta_{\text {am,OUT }} \approx \theta_{8}$ - temperature of air at the highest level of the cavity (outlet module) $\left({ }^{\circ} \mathrm{C}\right)$

$\theta_{\text {am,OUT }} \approx \theta_{2}$ - temperature of air exiting the cavity (outlet module) $\left({ }^{\circ} \mathrm{C}\right.$ ) 
The performance of a heat pump declines with the decrease of air temperature of outdoor climate $\theta_{\text {ae }}\left({ }^{\circ} \mathrm{C}\right)$ - fig. 3 , or for the problem solved by us, it is the decrease of air temperature at the outlet from the physical cavity $\theta_{\text {am,OUT }}\left({ }^{\circ} \mathrm{C}\right)$. There are two significant temperatures for the solved problem as we can see from the graphic dependence shown on fig. 3 :

- air temperature ensuring $100 \%$ performance of a heat pump - optimal $\theta_{\mathrm{ae}}=$ opt. $\theta_{\mathrm{am}, \mathrm{OUT}}$ $=+7^{\circ} \mathrm{C}-$ fig. 3

- air temperature ensuring $75-80 \%$ performance of a heat pump - critical $\theta_{\mathrm{ae}}=$ crit. $\theta_{\text {am, OUT }}=+1^{\circ} \mathrm{C}-$ fig. 3

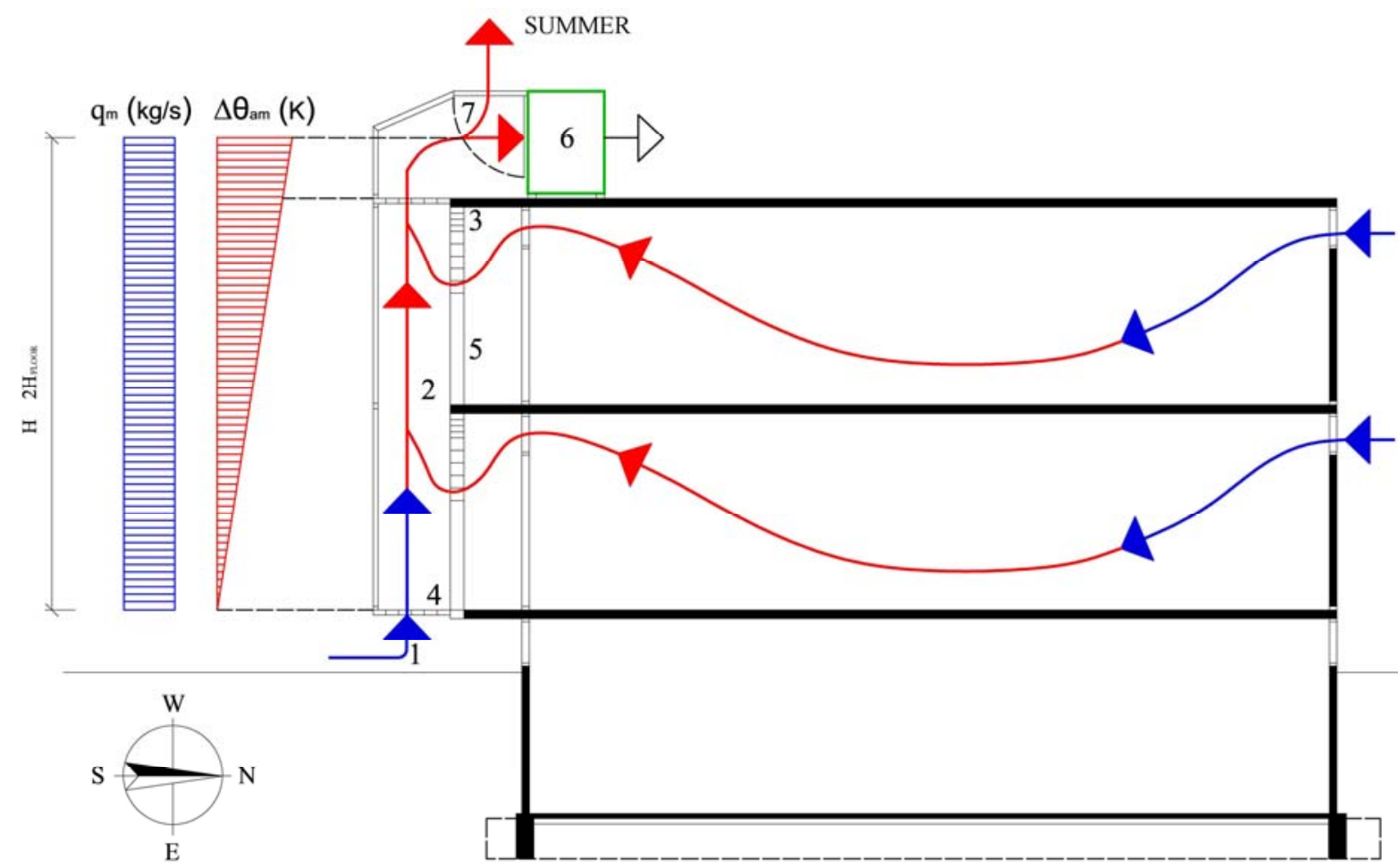

Figure 2: Scheme for utilization of the thermally conditioned air from the natural physical cavity - two level glazed space with effective height $\mathrm{H} \approx 2 \mathrm{H}_{\mathrm{FLOOR}}$ for heat pump 1- inlet of air into the cavity, 2-natural physical cavity, 3-sun protection, 4-ascendable shutter, 5-railing, 6-heat pump with primary energy of thermally conditioned AIR from the physical cavity, 7-revolving flap (regime WINTER - SUMMER)

\section{Methodology of the paper}

Methodology of the paper comes out from confronting the test reference year for the locality of Bratislava, modified for simulations of double-skin transparent façade of the building of National bank of Slovakia and from the long-term in-situ experiment, with the aim to quantify the energy regime of the natural physical cavity of double-skin transparent façade of the same building. 


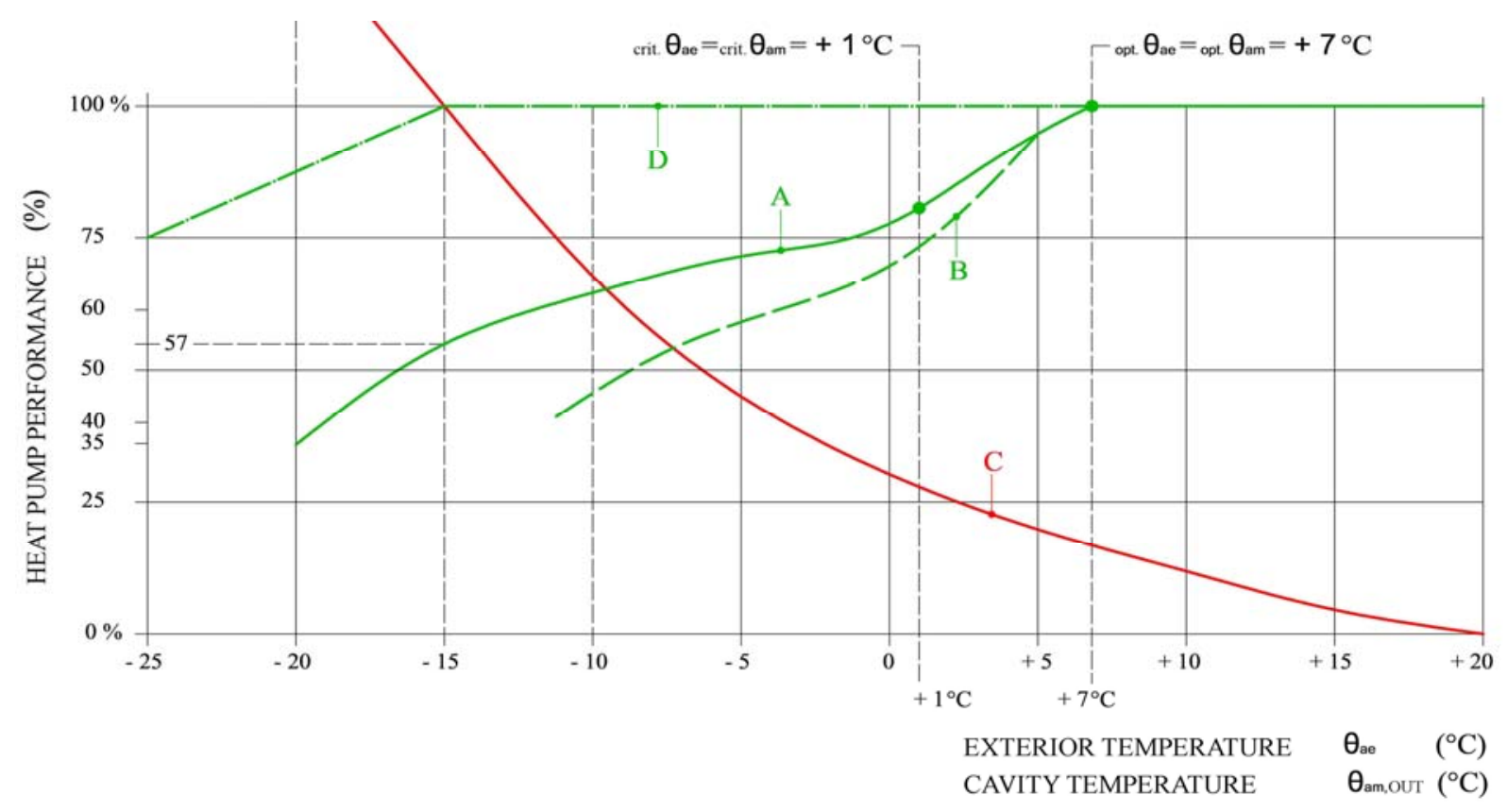

Figure 3: Dependence of decrease of the performance of heat pump with primary energy of AIR (AIR - WATER) from exterior - inlet temperature of air $\theta_{\mathrm{ae}}\left({ }^{\circ} \mathrm{C}\right)$

$\mathrm{A}$ - performance of inverter heat pump (with continuous output regulation), B - performance of heat pump ON/OFF (without inverter), $\mathrm{C}$ - energy demand for heating, D - attempts for new development technologies of heat pumps

Methodology for confronting the modified test reference year and the in-situ experiment lies in finding such an interval in the in-situ experiment, of which the average measured temperature of the outdoor climate corresponds to the average monthly temperature of the reference year in each distinctive month in the four seasons. The measured physical parameters of the cavity by the in-situ experiment in this time interval ( 3 to 5 days), can be then considered as characteristic parameters of natural physical cavity for given locality and optimal orientation $\left(\mathrm{SWW}-240^{\circ}\right)$.

Methodology for the second part of the paper utilizes the new knowledge about energy regime of natural physical cavities acquired from the in-situ experiment, based on the computational experiments by simulation program SSTT (STU Faculty of Civil Engineering) and the model of outdoor climate in the form of test reference year for the locality of Bratislava.

\section{Formatting requirements}

According to the methodology of the paper, selected intervals of energy regimes of natural physical cavity in the four distinctive seasons, document:

- for critical WINTER period - fig. 4, from which we can see that:

- for aver $\theta_{\mathrm{ae}, \mathrm{M}} \approx-2.3{ }^{\circ} \mathrm{C}$, the variance of this temperature is $\Delta \theta_{\mathrm{ae}} \approx 15 \mathrm{~K}\left(+7>\theta_{\mathrm{ae}}\left({ }^{\circ} \mathrm{C}\right)\right.$ $>-8)$, 
- in time intervals of day without direct solar radiation is the rise of temperature in the experimentally monitored natural physical cavity $\Delta \theta_{\mathrm{am}} \approx 3$ to $4 \mathrm{~K}$. This means that the temperature of air exiting the cavity is 3 to $4 \mathrm{~K}$ higher than the temperature of outdoor climate (transmission from the gradient of temperatures $\Delta \theta_{\mathrm{a}}=\theta_{\mathrm{ai}}-\theta_{\mathrm{ae}, \mathrm{M}} \approx 23.3 \mathrm{~K}$ ).

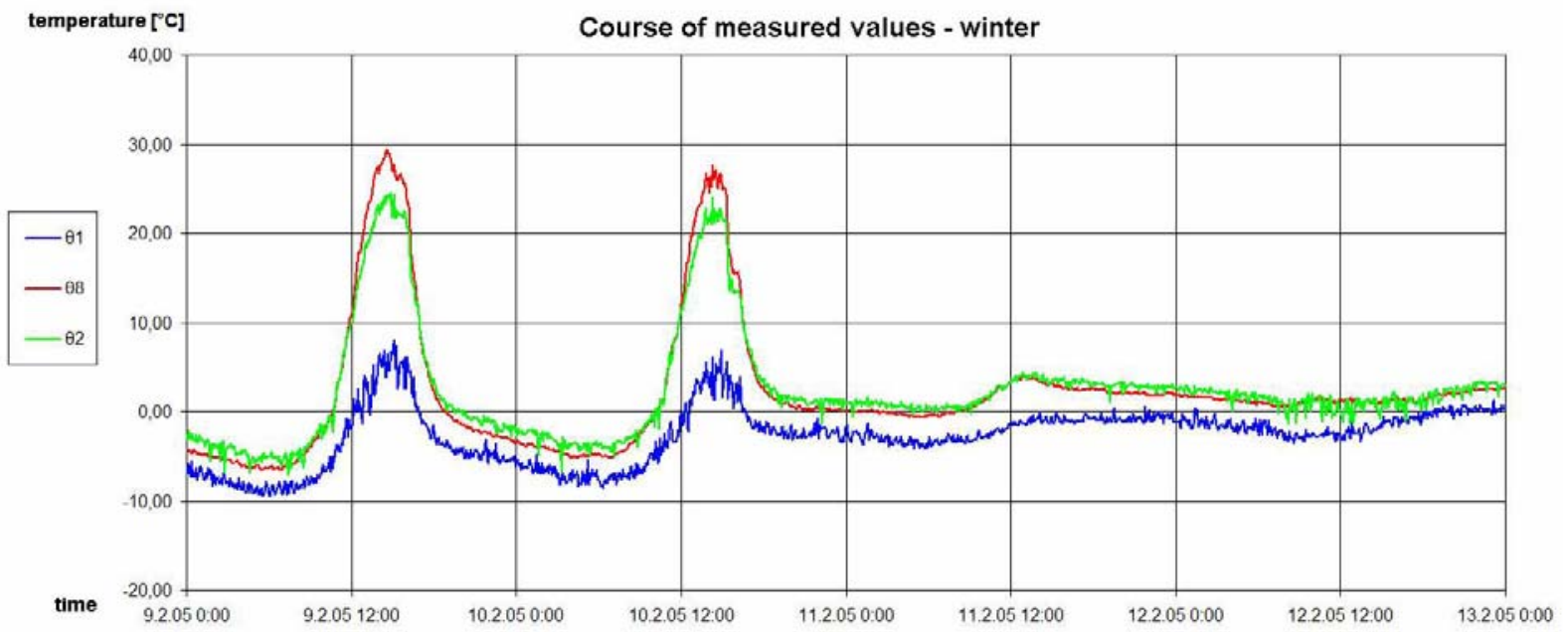

Figure 4: Characteristic regime of natural physical cavity in winter period

Table 1: The experimentally determined parameters of energy regime of natural physical cavity of corridor type $(\mathrm{w}=600 \mathrm{~mm})$, with effective height of one floor $\left(\mathrm{H}=\mathrm{H}_{\mathrm{FLOOR}}\right)$, optimal orientation ( $\left.\mathrm{SWW}-240^{\circ}\right)$, modified for the test reference year in distinctive seasons, for the locality of Bratislava $\left(\varphi=48^{\circ} 10^{\prime}, \lambda_{z}=17^{\circ} 08^{\prime}, \mathrm{h}=138 \mathrm{~m}\right)$

\begin{tabular}{|c|c|c|c|c|c|c|c|c|}
\hline \multirow{4}{*}{$\begin{array}{l}\text { DISTINCTIVE } \\
\text { SEASON }\end{array}$} & \multicolumn{4}{|c|}{$\begin{array}{c}\text { PARAMETERS OF OUTDOOR CLIMATE } \\
\text { TEST REFERENCE YEAR IDENTICAL WITH THE } \\
\text { SELECTION OF INTERVAL OF IN-SITU EXPERIMENT }\end{array}$} & \multicolumn{4}{|c|}{$\begin{array}{l}\text { PARAMETERS OF ENERGY REGIME OF } \\
\text { NATURAL PHYSICAL CAVITY } \\
\text { LONG-TERM IN-SITU EXPERIMENT }\end{array}$} \\
\hline & \multirow{3}{*}{$\begin{array}{c}\text { AVERAGE } \\
\text { MONTHLY } \\
\text { TEMPERA- } \\
\text { TURE } \\
\text { aver } \theta_{\text {ae, u }} \\
\left({ }^{\circ} \mathrm{C}\right)\end{array}$} & \multirow{3}{*}{$\begin{array}{l}\text { VARIANCE } \\
\text { OF } \\
\text { TEMPERA- } \\
\text { TURE } \\
{ }^{\Delta \theta_{\infty}} \\
(\mathrm{K})\end{array}$} & \multirow{3}{*}{$\begin{array}{l}\text { LOWEST } \\
\text { TEMPERA- } \\
\text { TURE } \\
\\
\min \theta_{\infty} \\
\left({ }^{\circ} \mathrm{C}\right)\end{array}$} & \multirow{3}{*}{$\begin{array}{l}\text { HIGHEST } \\
\text { TEMPERA- } \\
\text { TURE } \\
{ }_{\max . \theta_{\infty}} \\
\left({ }^{\circ} \mathrm{C}\right)\end{array}$} & \multicolumn{2}{|c|}{ OUTLET TEMPERATURE } & \multicolumn{2}{|c|}{$\begin{array}{l}\text { RISE OF TEMPERATURE AT } \\
\text { DIRECT SUN RADIATION }\end{array}$} \\
\hline & & & & & MINIMUM & MAXIMUM & WITHOUT EFF. & WITH EFF. \\
\hline & & & & & $\begin{array}{l}\min \theta_{\text {am,out }} \\
\left({ }^{\circ} \mathrm{C}\right)\end{array}$ & $\begin{array}{c}\max . \theta_{\text {am, out }} \\
\left({ }^{\circ} \mathrm{C}\right)\end{array}$ & $\begin{array}{l}\Delta \theta_{\mathrm{am}} \\
(\mathrm{K})\end{array}$ & $\frac{\Delta \theta_{m}}{(K)}$ \\
\hline $\begin{array}{l}\text { WINTER } \\
01 \\
\text { JANUARY }\end{array}$ & $-2,3$ & 15 & -8 & +7 & -5 & +30 & $3-4$ & $18-23$ \\
\hline $\begin{array}{c}\text { SPRING } \\
04 \\
\text { APRIL }\end{array}$ & $+8,7$ & 12 & +7 & +19 & +8 & +34 & $1-2$ & $10-15$ \\
\hline $\begin{array}{l}\text { SUMMER } \\
07 \\
\text { JULY }\end{array}$ & $+19,6$ & 20 & +15 & +35 & +16 & +52 & $0-1$ & $15-20$ \\
\hline $\begin{array}{c}\text { AUTUMN } \\
10 \\
\text { OCTOBER }\end{array}$ & $+10,5$ & 12 & +7 & +19 & +4 & +36 & $2-3$ & $12-17$ \\
\hline
\end{tabular}

Summary analysis of the experimentally determined parameters of the energy regime of the mentioned natural physical cavity documents table 1 . We can see that in the problem solved by us, for the optimally oriented cavity of corridor type with the effective height of one floor 
is the utilization of thermally conditioned air from the physical cavity as a primary energy source of a heat pump not suitable. In the critical winter period, the air exiting the cavity is of negative temperatures $-5^{\circ} \mathrm{C} \leq \theta_{\mathrm{am}, \text { out }}<$ crit. $\theta_{\mathrm{am}}=+1^{\circ} \mathrm{C}-$ fig. 4 , fig. 3 .

\section{New knowledge about energy regime of physical cavity and the possibilities of its utilization}

Solution to the mentioned problem forces us to look for ways of increasing the temperature of the air exiting the natural physical cavity in the winter period with such parameters which fulfill criteria: $\theta_{\text {am,out }} \geq+1^{\circ} \mathrm{C}=$ crit. $\theta_{\text {am }}$ or $\theta_{\text {am,out }} \geq+7{ }^{\circ} \mathrm{C}=$ opt. $\theta_{\text {am }}$ - fig. 3 .

There are several ways that lead to an increase of the temperature of air exiting the physical cavity:

1. decrease of air flow $\mathrm{q}_{\mathrm{m}}(\mathrm{kg} / \mathrm{s})$ through physical cavity - fig.5

2. increase of effective height of physical cavity, e.g. $\mathrm{H}=2 \mathrm{H}_{\mathrm{FLOOR}}-$ fig. 2 , or $\mathrm{H}=$ $\mathrm{n} . \mathrm{H}_{\mathrm{FLOOR}}(\mathrm{m})-$ fig. 5 .

3. increase of the effective height of a physical cavity in the combination with regulation of air flow within, documents fig. 5.

4. modification of the physical cavity with openings for inlet (outlet) of air on each floor with an effective height max $\mathrm{H}=6 \mathrm{H}_{\mathrm{FLOOR}}$ in accordance with the new knowledge about geometric classification of natural physical cavities.

Suggested modifications of the physical cavity lead to wide possibilities of variations in the creation of required parameters of energy regime, utilizable for a heat pump with primary energy of thermally conditioned AIR - fig.5.

\section{Conclusions}

Thermally conditioned air in a natural physical cavity with effective height $\mathrm{H}=\mathrm{H}_{\mathrm{FLOOR}}$ is in terms of energy regime in winter period with its parameters not suitable for requirements of function of a heat pump with primary energy of AIR without additional energy source that supplements reduced performance of the pump at low entering temperatures.

Variations of effective height of physical cavity $\mathrm{H}(\mathrm{m})$, modified by the regulation of air flow $\mathrm{q}_{\mathrm{m}}(\mathrm{kg} / \mathrm{s} . \mathrm{m})$ in acceptable interval $0.2<\mathrm{q}_{\mathrm{m}}(\mathrm{kg} / \mathrm{s} . \mathrm{m})<0.8$, expressing the effective efficiency of physical cavity, provide wide possibilities in the design process of cavities of the required physical parameters crit. $\theta_{\mathrm{am}, \mathrm{OUT}} \geq+1^{\circ} \mathrm{C}$. In the characteristic winter period - fig. 4 , table 1 , with the lowest temperature of outdoor climate min. $\theta_{\mathrm{ae}} \approx-8^{\circ} \mathrm{C}$, this required critical parameter is reached at rise of temperatures in the cavity $\Delta \theta_{\mathrm{am}}=\theta_{\mathrm{am}, \mathrm{OUT}}-\theta_{\mathrm{am}, \mathrm{IN}} \approx 10 \mathrm{~K}-$ fig. 5 .

\section{Acknowledgements}

This paper was supported by the Slovak research and development agency under contract no. APVV0624-10. 


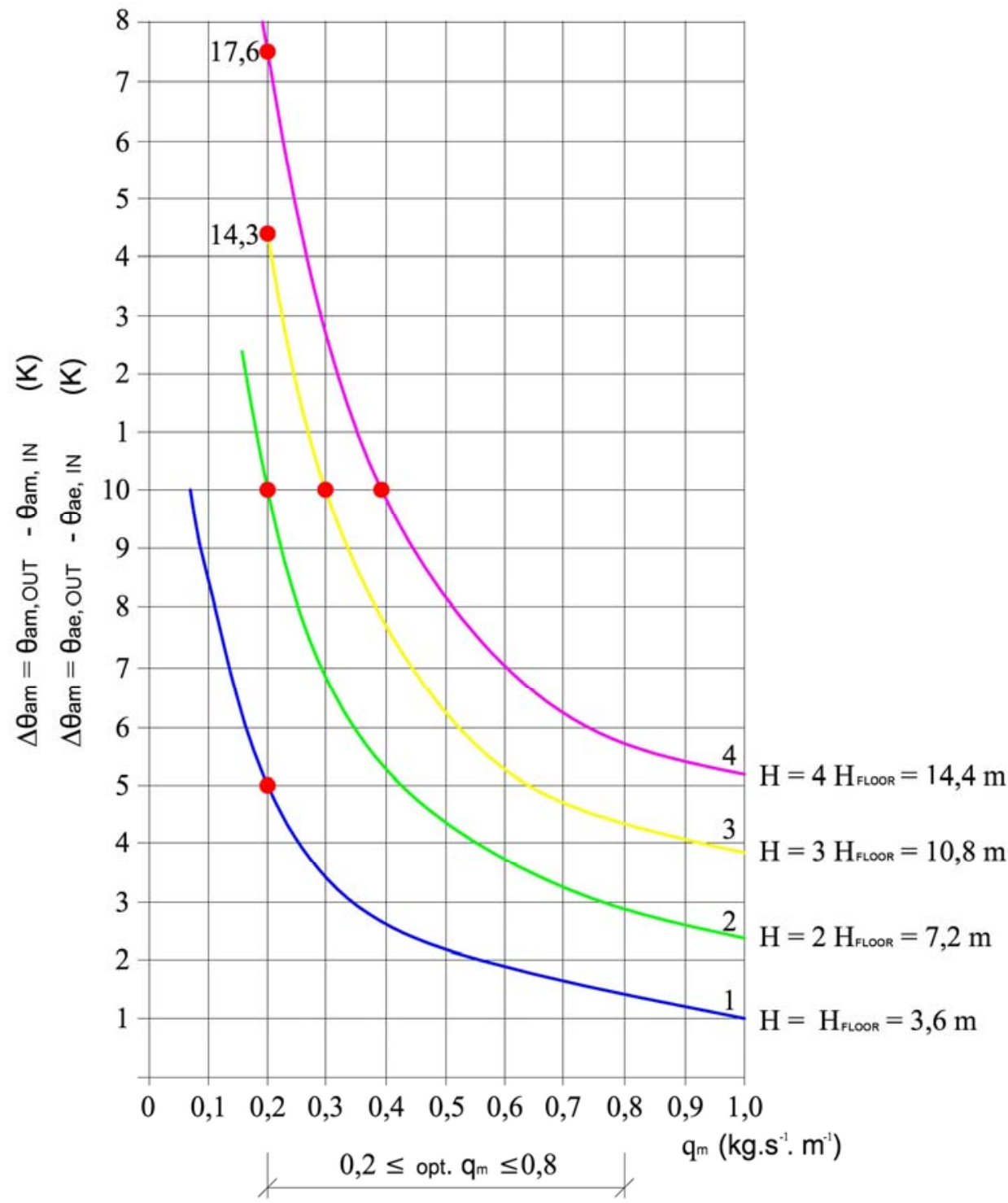

Figure 5: Graphic dependence $\Delta \theta_{\mathrm{am}}=\mathrm{f}\left(\mathrm{q}_{\mathrm{m}}\right)$ for a natural physical cavity of corridor type of the double-skin transparent façade with closed circuit in winter period. South orientation (S). Average approximate values for the climatic conditions of the test reference year in winter period in the locality of Bratislava.

\section{References}

[1] Bielek, B., Bielek, M. \& Palko, M. (2002). Double Skin Transparent Facades of Buildings, $1^{\text {st }}$ volume. Bratislava: Coreal.

[2] Bielek, B., Bielek, M., Kusý, M. \& Paňák, P. (2002). Double Skin Transparent Facades of Buildings, $2^{\text {nd }}$ volume. Bratislava: Coreal. 
[3] Bielek, B., Bielek, M. \& Szabó, D. (2009). Natural Physical Cavity Regime of Double-Skin Facade in Windless Climate Conditions - Long Term Experiment In-situ. Building Research Journal. Vol.57, 2009, No.3-4, p.233-246, ISSN 1335-8863

[4] Bielek, B., Bielek, M. \& Szabó, D. (2010). New Knowledge about Regime of Natural Physical Cavity of Double-Skin Transparent Facade under Wind Climate Conditions - Long Term Insitu Experimental Research. Technical transactions - Czasopismo techniczne, Issue 5, Year 106, 2-B/2010, p.11-23, ISSN 0011-4561

[5] Cihelka, J. (1994). Solární tepelná technika. Praha, Nakladatelství T. Malina.

[6] Compagno, A. (1995). Intelligent Glass Facades - Material Practice Design. First edition. Basel-Boston-Berlin : Birkhäuser Verlag. 